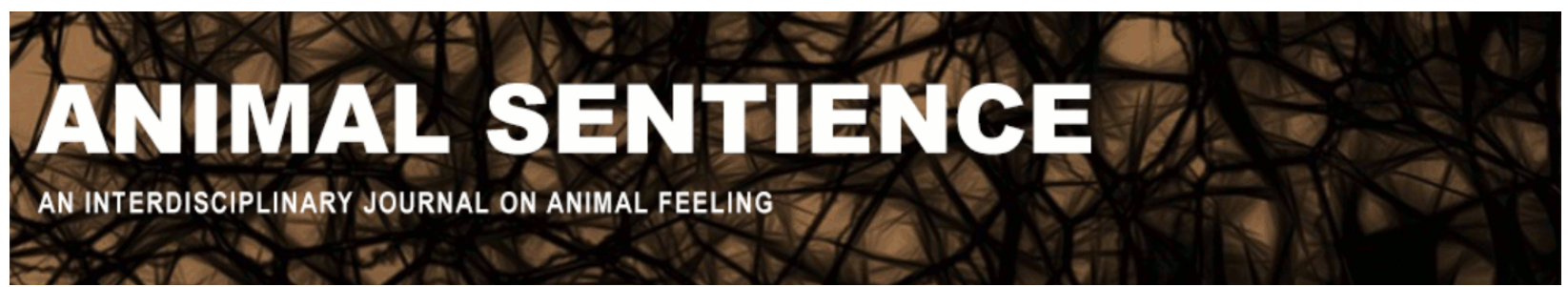

Pierce, Jessica (2017) Understanding animal suicide and death can lead to better end-of-life care. Animal Sentience 20(6)

DOI: $10.51291 / 2377-7478.1291$

Date of submission: 2018-01-06

Date of acceptance: 2018-01-09

(c) (†)

This article has appeared in the journal Animal

Sentience, a peer-reviewed journal on animal

cognition and feeling. It has been made open access,

free for all, by WellBeing International and deposited

in the WBI Studies Repository. For more information,

please contact

wbisr-info@wellbeingintl.org.

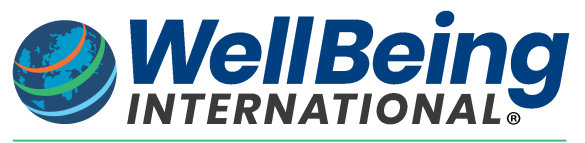

SOLUTIONS FOR PEOPLE, ANIMALS AND ENVIRONMENT 


\title{
Understanding animal suicide and death can lead to better end-of-life care \\ Commentary on Peña-Guzmán on Animal Suicide
}

\author{
Jessica Pierce \\ Center for Bioethics and Humanities, University of Colorado
}

\begin{abstract}
Peña-Guzmán's target article on animal suicide will help inform end-of-life care for animals by emphasizing the need for a broad research focus on animal thanatology. Greater scientific understanding of the continuum of death-related awareness, experiences, and behaviors will help us improve veterinary care for animals at the end of life.
\end{abstract}

Jessica Pierce is a bioethicist, writer, and affiliate faculty member at University of Colorado. She has a Master of Theological Studies from Harvard and a PhD in Religious Studies from the University of Virginia. Her interests include animal hospice and palliative care, the ethics of dog ownership, and environmental bioethics. www.psychologytoday.com/experts/jessicapierce-phd

I'd like to speak to a few of the ways in which Peña-Guzmán's (2017) essay “Can nonhuman animal commit suicide?" might help inform end-of-life care for animals. I'll focus particularly on the care of companion animals, but we can extend the discussion to include all captive animals.

Peña-Guzmán observes that although the concept of suicide is extraordinarily complex within the human framework, "the concept seems to lose all its complexity when applied to nonhuman animals." This same observation extends beyond the narrow issue of suicidal behavior to encompass nearly all discussion of animals and death. Within human end-of-life care, we have a complex and very nuanced vocabulary about ending and extending our own lives and the lives of patients who cannot speak for themselves. The vocabulary continues to evolve (e.g., "assisted suicide" becomes "medical aid in dying"). Within the animal realm, nuanced terminology such as "palliative sedation" has yet to develop, and "euthanasia" is still used as a very blunt tool, without the ability to discriminate between killing a healthy animal and hastening the death of a terminally ill, actively dying patient.

The paucity of our vocabulary for talking about animal death reflects the very problem that Peña-Guzmán identifies: because we have assumed that animals don't have what it takes to think about death - their own or anybody else's - we haven't really asked serious questions about death-related behaviors, rituals, suicide, and the animal's own experience at the end of life. This means that we haven't really taken the measure of who animals are as dying patients. In the care of animals, you often hear anguished pet owners asking, "When will I know it is time?" 
Instead of entering into this question deeply - as a scientific and ethical question about what animals are feeling and what this means for caregivers - we skate the surface. Instead of science, we use clichés ("a month too soon is better than an hour too late") and animal communicators ("Fluffy tells me she is ready to be released"). These may comfort a human caregiver, but they don't really offer much help to the animal patients themselves, nor do they really help guide medical decision-making in concrete ways that focus on the animals. Instead of clichés, we need a rich and well-developed understanding of the (species-specific) animal death experience and a complex, nuanced vocabulary for talking about what animals might feel, want, and need at the end of life.

To take a concrete case related to suicide, how do we understand the behavior of a dog or cat who decides, at some point, to stop eating and drinking? An animal refusing food or losing interest in food (two different things?) is a common problem in palliative and hospice care. On the one hand, many animals who are ill or in pain will experience decreased appetite. Inappetence is a "medical" condition to which we should, as palliative caregivers, respond. Yet how do we distinguish between "medical inappetence" and an animal's "decision" to stop eating and drinking as a suicidal act? (And, as in the human debate, should the decision to hasten your own death if you are dying from an incurable disease really be labeled "suicide"?) Voluntary refusal of food and fluid (or VRFF, as it is known in the human literature) seems to fall into Peña-Guzmán's compendium of "self-initiated behaviors that ultimately produce self-harm or death." Yet how do we untangle all the threads, so that our response to individual animals affirms their choice, if they are indeed making a choice, to "produce death," while ensuring that we are responding to uncomfortable symptoms such as nausea and pain? Refusal to eat is often met with one of two responses: (1) medication to stimulate appetite or, perhaps more likely, (2) what the poet Billy Collins calls "the needle of oblivion." But what about a third option? When might we respect animals' autonomous choice to end their own life by not eating?

A refusal to eat points to a larger issue of dissent. Peña-Guzmán notes - and I am in complete agreement - that animals have the cognitive ability to dissent from various kinds of interactions with humans and that we need to take account of this "morally salient capacity" when designing research protocols that involve animals. Moving the issue, again, into the realm of companion animal end-of-life care, we should continue to find ways to provide medical care that is attentive to consent, assent, and dissent. We too often simply make this a throw-away point: "animals can't speak so we have to decide for them." Animals cannot assent or dissent or consent - these are human capacities. (Again, the strange denial of evolutionary continuity that Peña-Guzmán notes.) This paternalism often goes unchecked and is always unwarranted. Because we haven't taken accurate measure of who animals are in relation to their own lives and deaths, we fail to see that they, too, play a role in the drama of their own passing - indeed, perhaps they should play the main part! We have an opportunity to do much better to accommodate the "volitional and decisional capacities" of animals.

This is particularly thorny when it comes to one of the most common treatments for pain and suffering in our companion animals: our handy needle of oblivion. Can the kind of discussion Peña-Guzmán is initiating help us improve the process of assessing quality of life in animals? Can 
it help us develop relatively objective tools to decide when an animal is "ready" to die? I think so. In a footnote, Peña-Guzmán refers to the notion that suicide might be viewed as something that happens when animals lose their "will to live." The phrase "will to live" is beginning to be used more in animal hospice and palliative care, but it is still often met with suspicion by veterinarians, who think it smacks of anthropomorphism. An animal can't have a "will to live" - this is a human thing. (An interesting side note here: veterinarians are, by and large, unaware of the cognitive ethology literature; I've had heated conversations with vets who refuse to talk about animal feelings because they think talking about animal feelings is unscientific. The American Animal Hospital Association finally endorsed the idea that animals are sentient - in 2012! AAHA's guidelines on hospice and palliative care (Bishop et al. 2016) completely ignore the possibility that animals may have agency, may consent or dissent, or may care one way or another about their own death. Some "unanswered questions" about animal cognition are relegated to a short paragraph at the end of the guidelines. These "unanswered questions" include whether animals have self-awareness, make choices, or think about past or future.)

Because most companion animals are euthanized at some point before or during their decline, we don't have a lot of information about death-related behaviors, including what might be classified as suicides. As hospice-assisted natural death becomes a more socially acceptable option for animals and their human companions, the veterinary professionals providing this kind of care can help build a database of information about the dying process, and about how to understand and support patient choice within this realm. (To do this, however, veterinarians need to start working more closely with those studying animal sentience.)

Peña-Guzmán has done us a great service by challenging us to think more carefully and with more open minds about animals at the end of life. There is so much rich and exciting work to be done in the realm of animal death, including suicide. This research has immediate and practical implications for veterinary medicine and for humans who share their lives with animals and have committed themselves, as many of us have, to seeing our companions through, all the way to the bitter end.

\section{References}

Bishop, G., Cooney, K., Cox, S., Downing, R., Mitchener, K., Shanan, A., Soares, N., Stevens, B., \& Wynn, T. (2016) 2016 AAHA/IAAHPC End-of-Life Care Guidelines. Journal of the American Animal Hospital Association, 52(6), 341-356.

Peña-Guzmán, D. M. (2017) Can nonhuman animals commit suicide? Animal Sentience (20)1. 